\title{
CURRÍCULO AFROCENTRADO: IMPLICAÇÕES PARA A FORMAÇÃO DOCENTE
}

\section{Carla Verônica Albuquerque Almeida*}

RESUMO: A educação afrocentrada constitui-se como um desafio na contemporaneidade, na busca de assegurar o lugar dos africanos e afro-brasileiros, como sujeitos da sua própria história e da sua cultura. Neste contexto, torna-se fundante repensar a formação docente, bem como o currículo dos cursos de formação inicial e continuada de professores. É nessa direção que este texto se propõe a refletir sobre o currículo e suas implicações para a formação de professores, a partir do paradigma proposto por Molefi Asante. Inicialmente discute as interfaces para uma educação afrocêntrica, na perspectiva de transpor os limites de uma educação eurocêntrica, discriminatória e excludente. Apresenta aspectos da constituição histórica e evolutiva do currículo a partir das teorias curriculares e a contribuição do currículo afrocentrado para a efetivação de uma formação e prática pedagógica docente com vistas a ampliar, valorizar e visibilizar os valores, as histórias e os saberes africanos e afro-brasileiros.

Palavras-chave: Afrocentricidade. Currículo. Formação de Professores

ABSTRACT: Afro-centered education constitutes a challenge in contemporary times, in the search to secure the place of Africans and Afro-Brazilians as subjects of their own history and culture. In this context, it becomes fundamental to rethink teacher education as well as the curriculum of initial and continuing teacher training courses. It is in this direction that this text proposes to reflect on the curriculum and its implications for teacher training, from the paradigm proposed by Molefi Asante. Initially it discusses the interfaces for an Afrocentric education, with a view to crossing the limits of a Eurocentric, discriminatory and excluding education. It presents aspects of the historical and evolutionary constitution of the curriculum based on the curricular theories and the contribution of the afrocentrado curriculum to the accomplishment of a pedagogical training and pedagogical practice with a view to amplifying, valuing and making visible the values, histories and African and Afro- Brazilians.

Keywords: Afrocentricity. Curriculum. Teacher training

[...] não se pode assumir uma orientação voltada à agência africana sem respeitar a dimensão criativa da personalidade africana e dar um lugar a ela. Deve haver a compreensão dos elementos africanos linguísticos, psicológicos, sociológicos, filosóficos e dos valores, hábitos, costumes e religião sem impor interpretações eurocêntricas ou não-africanas (ASANTE, 2009, p. 98) .

\footnotetext{
* Doutora em Educação (UNEB), Professora Adjunta da Universidade da Integração Internacional da Lusofonia Afro-brasileira - UNILAB (Campus Malês) Instituto de Humanidades e Letras. Pesquisadora dos Grupos de Pesquisa em Família, (auto)biografia e poética - FABEP (UCsal) e em Educação Afrocentrada (UNILAB) E-mail: carlaalmeida@unilab.edu.br.
}

\section{Educação e afrocentricidade}

Os fios que trançam a trajetória histórica do cenário brasileiro revelam que a educação esteve durante muito tempo, reservada apenas a uma parcela da população, de caráter elitista, privando a maioria deste direito. Tal fato demarca e acentua um quadro de exclusão social, ao mesmo tempo implícita e visivelmente explícita aos nossos olhos, marcado por desigualdades sociais, culturais e econômicas, evidenciado e legitimado pelo contexto socioeducativo e pela cultura eurocêntrica; desconsiderando a exemplo da cultura negra, a dimensão cria-

ALMEIDA, Carla Verônica Albuquerque. Currículo afrocentrado: implicações para a formação docente. Revista Sul-Americana de Filosofia e Educação. Número 31: mai.-out./2019, p. 71-86. DOI: https://doi.org/10.26512/resafe.vi30.28257 
tiva da personalidade africana, silenciada e marginalizada pela sociedade vigente.

Nesse aspecto, foi negado o direito a educação a população negra, em detrimento da classe elitizada pois, excluídos de fato e de direito, “[...] viram suas oportunidades educacionais se diluírem em um arsenal de dispositivos e argumentações, mediante os quais se justifica sua baixa ou nula presença nos âmbitos educacionais" (GENTILI, 2009, p.1061). O que denota a desigualdade social, frente às políticas sociais básicas, ainda presentes na contemporaneidade, que não conseguiu diluir efetivamente os seus efeitos nefastos sobre a sociedade.

A educação torna-se assim a quimera de um sistema que consagra a distribuição desigual dos benefícios e a negação de direitos e de valores, desvela assimetrias étnicoraciais, cujo olhar preconceituoso e racista rompe relações e identidades culturais civilizatórias. As culturas africanas foram invisibilizadas e destruídas, fecundando um terreno racista com "zonas cinzentas e viciadas do pensamento, pautadas no eurocentrismo" (AZEVEDO, 2016, p. 239), fértil de estereótipos e estigmas imputados ao povo afro-brasileiro, reificando posturas e posições preconceituosas, excludentes e conservadoras.

A concretização do direito à educação se faz pela igualdade nas oportunidades e condições de acesso ao sistema escolar e ao ensino de qualidade, que busque superar efetivamente as condições que geraram a exclusão. "Somos filhos do tempo, da cultura e [...] dos processos educativos que as sociedades criam e recriam. 'Húmus' que podem fecundar ou apodrecer" (GENTILI, 2009, p. 1070). Um processo de "exclusão includente", no qual os mecanismos se recriam e assumem novas fisionomias, no contexto de dinâmicas de inserção e inclusão que se expressam insuficientes ou, em alguns casos, inócuos para reverter as condições de isolamento, marginalização, negação e segregação de direitos educacionais.

Ao romper com os limites préestabelecidos pela ideologia dominante, a educação é capaz de instrumentalizar a sociedade para uma revolução humana como política de inclusão social, não para reproduzir o interesse do poder hegemônico, mas que considere "outras presenças, respeite a diversidade, oportunize o direito à história; o que representa efetivamente, uma educação que contemple os sujeitos em suas diferenças, sem acepções e inferiorizações" (CANDAU, 2012, p. 26). Uma educação que transponha limites com vistas a transmitir, ampliar e visibilizar os valores e saberes afrodescendentes, considerando suas histórias, suas identidades como aspectos fundantes que articulem as condições materiais às dinâmicas sociais, culturais, identitárias e políticas.

Neste cenário, torna-se imperioso uma educação politicamente engajada, a favor de demandas diferenciadas, colocando as etnias africanas e afro-brasileiras como protagonistas de sua trajetória histórica cultural. "Estudávamos a África em sua relação com a Europa, e não como as culturas africanas se relacionavam entre si” (ASANTE 2009, p. 101). O paradigma da afrocentricidade emerge neste contexto com o firme propósito de manter o africano como centro, como sujeito e não como objeto, demarcar o seu lugar e sua identidade, "dar voz" e visibilidade a sua própria história. 
A ideia de afrocentricidade é concebida por Molefi Asante nos anos 8o, como "um tipo de pensamento, prática e perspectiva que percebe os africanos como sujeitos e agentes de fenômenos atuando sobre sua própria imagem cultural e de acordo com seus próprios interesses humanos" (ASANTE, 2009, p. 93). O que nos permite pensar numa releitura da imagem do negro, até então veiculada por preconceitos e estereótipos, que nos encaminhe para uma educação genuinamente afrocentrada. Para o autor, a afrocentricidade "é a conscientização sobre a agência dos povos africanos, a chave para a reorientação e a recentralização, de modo que a pessoa possa atuar como agente, e não como vítima ou dependente" (p. 94), para que não mais se localize e atue à margem da experiência eurocêntrica.

Na concepção de Asante (2009), a perspectiva eurocêntrica descentrou os africanos, posto que suas experiências não estavam alicerçadas na sua própria história e neste sentido, evidencia a afrocentricidade sob o aspecto da conscientização, o qual orienta o sujeito quanto as opressões sofridas, deixando a posição de dependência e, busque as possíveis vias de libertação através de sua agência, ou seja, "a capacidade de dispor dos recursos psicológicos e culturais necessários para o avanço da liberdade humana” (ASANTE, 2009, p. 94). Mazama corrobora com Asante (2009), ao afirmar que a afrocentricidade surge como um novo paradigma para desafiar o eurocentrismo branco, o qual imputou a sua supremacia aos africanos, tornando-os invisíveis, em muitos casos. "O que se sugere é que, em vez disso, os africanos se reancorem, de modo consciente e sistemático, em sua própria matriz cultural e histórica, dela extraindo os critérios para avaliar a experiência africana” (MAZAMA, 2009, p. 114). E nessa direção, se veja como "centro" da sua história, sua cultura e ancestralidade.

\begin{abstract}
Os termos "centro" e "afrocentrado, as expressões "estar centrada" ou ser "uma pessoa afrocentrada" dizem respeito às perspectivas de localização dentro de suas próprias referências históricas e culturais, sem nenhum desmerecimento às outras. Mas, evitando a marginalização ou invisibilização de sua própria trajetória histórica e cultural e, por conseguinte, todas as consequências negativas de não se reconhecer no projeto civilizatório e de produção de saberes ao longo da história da humanidade. (NOGUERA, 2010, p. 3).
\end{abstract}

Ao ocupar o centro das discussões, o paradigma afrocêntrico reconhece como fundante estabelecer o lugar dos africanos na história, mediante suas próprias referências históricas e culturais, o que converge para uma educação sem desmerecer e inferiorizar outras civilizações; mas que descortine uma leitura "dos papéis de todas as atrizes e atores na produção dos diversos saberes" (NOGUERA, 2010, p. 4) que se contraponham ao daltonismo cultural da escolarização, que problematizem as relações assimétricas de poder, tendo como condição basilar uma educação epistemológica e dialógica intercultural que se reoriente em parâmetros africanos importantes e basilares na construção de uma educação antirracista - afrocentrada. 
O que estamos defendendo não é apenas a rejeição ou superação da educação eurocêntrica em nome da liberdade e humanidade abstratas e sim a criação de modelos afrocentrados de educação para que os valores africanos sejam preservados e transmitidos e, assim, possamos, de fato, construir uma sociedade intercultural. Dito de outra forma, uma educação que problematize o modelo bancário não é necessariamente um modelo que reconheça, aceite, preserve e transmita os valores africanos e afro-brasileiros (BENEDICTO, 2016, p. 211-212)

O autor reafirma a importância de modelos afrocentrados de educação, que se oponham a ideologia da opressão e da alienação. Uma educação em que os valores africanos e afro-brasileiros se presentifiquem, não de forma velada, mas num movimento consciente, dialético e dialógico que reconheça e assegure a produção de conhecimentos, as práticas educativaspedagógicas e consequentemente, a formação integral do sujeito.

Nos liames destas reflexões, cabe salientarmos que os diversos movimentos de resistência e opressão, a visibilidade da luta do Movimento Negro em favor da eliminação de todos os tipos de preconceito, discriminação e racismo, impulsionou a promulgação da Lei 10.639/o3'; a qual altera

\footnotetext{
${ }^{1}$ A Lei 10.639/03 foi regulamentada pelo Conselho Nacional de Educação, por meio de seu Conselho Pleno, que elaborou o Parecer no $\mathrm{CNE} / \mathrm{CP}$ oo3/o4 de 10/03/2004, o qual estabelece as Diretrizes Curriculares Nacionais para a Educação das Relações ÉtnicoRaciais e para o Ensino de História e Cultura AfroBrasileira e Africana. A referida Lei foi atualizada pela Lei 11645/o8 para incluir no currículo oficial da
}

o texto original da Lei de Diretrizes e Bases da Educação Nacional de 20 de dezembro de 1996. Estabelece a obrigatoriedade do ensino de História e Cultura Africana e Afro-Brasileira, nos currículos da Educação Básica e do Ensino Superior, apresentando como princípios:

[...] análises das relações sociais e raciais no Brasil; de conceitos e de suas bases teóricas tais como racismo, discriminações, intolerância, preconceito, estereótipo, raça, etnia, cultura, classe social, diversidade, diferença, multiculturalismo; de práticas pedagógicas, de materiais e de textos didáticos, na perspectiva da reeducação das relações étnicoraciais e do ensino e aprendizagem da História e Cultura dos Afrobrasileiros e dos Africanos (BRASIL, 2004, p.23).

Os princípios acima explicitados têm como pressupostos a construção de uma educação que possibilite engendrar saberes e práticas emancipatórias que reconheçam de forma não discriminatória "o interesse pela localização psicológica, cultural, histórica ou individual das pessoas; o compromisso com a descoberta do lugar africano como sujeito; a defesa dos elementos culturais africanos; o compromisso com uma nova narrativa da história da África" (ASANTE, 2009), sobretudo nas suas múltiplas relações com a realidade africana e afrobrasileira.

\section{Da visão eurocêntrica à afrocentricida- de: a constituição do Currículo}

rede de ensino a obrigatoriedade da temática "História e cultura afro-brasileira e indígena". 
Dialogar sobre as articulações entre educação e afrocentricidade nos conduz a refletir sobre a importância do currículo, assim como a sua pertinência enquanto campo do conhecimento; o que fez emergir discussões que implicam em um repensar as formas de organização curricular existentes. O currículo está longe de ser um instrumento imparcial, uma vez que pode ser utilizado tanto como articulador de mudanças, quanto como elemento repressor, perpetuando um determinado modelo de educação e prática pedagógica.

A pluralidade de pressupostos de caráter filosófico, epistemológico, sociológico, ideológico e cultural, que fundamentam as visões dos grupos em determinado contexto e tempo histórico que se alternam no poder, alicerçam a concepção de currículo, considerado como "o resultado de uma seleção, de um universo mais amplo de conhecimentos e saberes determinados por teorias que decidem quais conhecimentos devem ser selecionados, justificando porque 'esses conhecimentos' e não 'aqueles' devem ser selecionados [...] (SILVA, 2011, p.15). Assim, enquanto artefato de seleção, de permanência ou renovação dos conhecimentos, tornase fundante uma breve retrospectiva das teorias que contribuíram para a constituição do currículo, ao longo da história.

Os primeiros estudos teóricos sobre currículo surgiram nos Estados Unidos na década de 1920 e defendiam uma concepção tradicional de educação. O currículo era considerado enquanto um conjunto de fatos e conhecimentos a serem transmitidos aos estudantes, "traduz elementos da memória coletiva, expressão ideológica, política, ex- pressão de conflitos simbólicos, de descobrimento e ocultamento, segundo os interesses e jogos de força, daqueles que estão envolvidos (ou não) no processo educativo" (BERTICELLI, 2001, p. 168). Assim, a massificação da escolarização, que ensejava a desigualdade de acesso à educação, modelo defendido por Bobbitt, embasado nas teorias administrativas científicas de Taylor com ênfase "no processo de industrialização e dos movimentos imigratórios, impulsionou por parte de pessoas ligadas, sobretudo à administração da educação, a racionalização do processo de construção, desenvolvimento e testagem de currículos [...]" (SILVA, 2011, p.12). Nesse contexto, a escola, o conhecimento e a cultura permaneciam estáticos e não recebiam influências dos diversos aspectos políticos, sociais, econômicos, entre outros, presentes em nossa sociedade. $\mathrm{O}$ que reverbera para uma visão tradicional do currículo.

Na esteira de Bobbitt, mas considerando a relevância da filosofia e da sociedade como fontes fundantes para o currículo, o modelo proposto por Tyler priorizava a questão técnica centrada na organização e desenvolvimento da sociedade, atendendo a expectativa da ideologia dominante. Assim, em uma perspectiva essencialmente técnica, o currículo deveria centrar-se nos objetivos, ensino, instrução e avaliação posto que para "planejar um programa educacional e envidar esforços para um melhoramento continuado, conceber metas que têm em vista. [...] critérios para seleção de materiais, se esboça o conteúdo, se desenvolvem procedimentos de ensino e se preparam testes e exames" (TYLER, 1999, p. 2). 
Consideramos que tanto Bobbitt, quanto Tyler defendiam que "a tarefa do especialista em currículo era fazer o levantamento de habilidades, desenvolver currículos que permitissem que essas habilidades fossem desenvolvidas e, planejar e elaborar instrumentos de medição que possibilitassem dizer com precisão se elas foram realmente aprendidas" (SILVA, 2011, p. 24). E nesse sentido, o ensino deveria ser organizado para a formação de sujeitos para o mercado de trabalho.

Uma vez que a sociedade vigente na época, encontrava-se em processo de industrialização, caberia à escola em uma perspectiva tradicional, a responsabilidade de formar sujeitos capazes de atuar de forma eficiente na sociedade. Para as teorias tradicionais, o currículo apresenta-se como “o conjunto de objetivos de aprendizagem selecionados que devem dar lugar à criação de experiências apropriadas, com efeitos cumulativos avaliáveis, de modo que se possa manter o sistema numa revisão constante, para que se operem as oportunas reacomodações" (SACRISTÁN, 200o, p. 46). Destarte, a escola deveria ser pensada como um lugar estático e os conhecimentos organizados no currículo, desenvolvidos de forma mecânica, deveriam priorizar a cultura dominante, reforçando a construção de identidades sociais hegemônicas.

[...] os conteúdos que são desenvolvidos de forma explícita nas instituições de ensino e aquilo que é enfatizado nas propostas curriculares, chama a atenção a arrasadora presença das culturas que podemos chamar de hegemônicas. As cultu- ras ou vozes dos grupos sociais minoritários e/ou marginalizados que não dispõem de estruturas importantes de poder costumam ser silenciadas, quando não estereotipadas e deformadas, para anular suas possibilidades de reação (SANTOMÉ, 1995, p. 161).

O silenciamento e a marginalização das culturas consideradas inferiores, a exemplo das culturas negras, pela cultura hegemônica europeia, é reforçada no ambiente escolar pelas teorias tradicionais do currículo. Ainda que estas culturas estivessem presentes no currículo, suas histórias eram invisibilizadas, cedendo espaço para formulações racistas e preconceituosas que naturalizavam as desigualdades, reforçando a construção de estereótipos em torno de suas imagens.

O cenário histórico social da década de 60 , marcado por significativas transformações, decorrentes das insatisfações no âmbito político, econômico e social, as quais influenciaram as questões educacionais, assim como desencadearam escritos teóricos, expressou desagrados aos parâmetros estabelecidos pelos modelos tradicionais, influenciados por Bobbit e Tyler. Neste contexto, emergem as teorias críticas do currículo, evidenciadas a partir dos estudos que se opunham à cultura elitista eurocêntrica, a qual explorava e oprimia os sujeitos considerados marginalizados, em especial as populações africanas. Tais teorias ressaltam a construção de uma cultura escolar própria, baseada num esforço individualizado, "desconfiam do status quo, responsabilizando-o pelas desigualdades e injustiças 
sociais. São teorias de desconfiança, questionamento e transformação radical" (SILVA, 2011, p. 30).

Nesta perspectiva, a concepção do currículo técnico e hegemônico foi perdendo campo, deixa de ser visto como "[...] uma operação meramente cognitiva, em que certos conhecimentos são transmitidos a sujeitos dados e formados de antemão" (SILVA, 2011, p. 195), o que implicou na inclusão de temas de relevância social aos planos escolares. A construção curricular não é apenas uma questão técnica, mas abrange a tomada de decisões que envolvem interesses, divergências e conflitos. Reflete intencionalidades, estimula o surgimento de um currículo que problematize as identidades de classe, que possibilite a reflexão sobre possíveis diálogos com a cultura africana e afrobrasileira, até então negada pelas Teorias Tradicionais.

Na visão das teorias críticas do currículo, a escola é um espaço dinâmico e social e desta forma, deve oportunizar a tomada de consciência, sendo basilar, trabalhar com aspectos fundantes como "ideologia, reprodução cultural e social, poder, classe social, capitalismo, relações sociais de produção, conscientização, emancipação e libertação, currículo oculto e resistência" (SILVA, 2011, p. 17). Essa série de conceitos deve levar ao questionamento das desigualdades existentes e contribuir para a aquisição de conhecimentos sistematizados no currículo, que considere a participação dos sujeitos em todas as esferas, garantindo sua emancipação. O que nos possibilita inferir que os referidos conceitos subsidiam "a compreensão de que os currículos são ideologicamente situados e inseridos nas relações de poder, especialmente nos interesses das lutas de classe (EYNG, 2015, p. 36). Demarca-se aí uma estrutura que se formula e reformula a margem das diretrizes e definições oficiais. O que para Silva (2011), impele para uma visão de currículo como um artefato social que expressa desigualdade das classes e relação de poder na seleção dos saberes através da influência das questões econômicas e sociais.

Salientamos que frente as discussões sobre as teorias críticas, insere-se o currículo fenomenológico, o qual destaca a educação enquanto espaço de formação e de relações entre o mundo e os sujeitos. Nesse sentido, o currículo "é um local no qual docentes e aprendizes têm a oportunidade de examinar, de forma renovada, os significados da vida cotidiana que se acostumaram a ver como dados e naturais. O currículo é experiência, local de investigação e questionamento da experiência" (SILVA, 2011, p. 41). Nessa direção, ancorada na experiência, no mundo vivido, nos significados subjetivos e intersubjetivos, a perspectiva fenomenológica é "comovedoramente poética. Revela mais por evocar e sugerir do que por mostrar e convencer" (p. 42). Não obstante, a centralidade na história dos sujeitos, em suas experiências, suas singularidades, sua "essência"

Em suma, as reflexões permitidas pelas Teorias Críticas do Currículo, ao deslocarem "a ênfase dos conceitos simplesmente pedagógicos de ensino e aprendizagem para os conceitos de ideologia e poder, nos permitem ver a educação de uma nova perspectiva [...]" (SILVA, 2011, p.17). E nesse sen- 
tido, destacam um novo olhar em relação às questões da sociedade, da educação e consequentemente da escola, assim como possibilitam uma mudança de atitude para educadores e estudantes, ao colocarem o currículo como um espaço de poder e um campo de lutas onde "não existam mais opressores nem oprimidos e que não prevaleça uma classe sobre a outra, mas que prevaleça homens libertando-se" (FREIRE, 2007, p. 43). Cabe salientar que esta discussão não se encerra, posto que as teorias pós críticas tendem a ampliar as discussões em prol de um currículo ainda mais crítico.

A despeito da evolução percebida no campo curricular, as teorias pós-críticas demarcam seu espaço no cenário da educação a partir da década de 8o, fundamentadas no movimento multiculturalista, o qual impulsiona as diferentes manifestações culturais no âmbito da sociedade e a sua valorização, na "luta pela adoção de uma perspectiva culturalmente pluralista" (SILVA, 2016, p. 257). Assim, vinculados ao "conhecimento, identidade e poder, os temas da raça e da etnia ganham seu lugar na teoria curricular" (SILVA, 2011, p. 101), e dessa forma, produzem elementos de relações de poder.

As teorias pós-críticas continuam a enfatizar que o currículo não pode ser compreendido, sem uma análise das relações de poder nas quais está envolvido. Nas teorias pós-críticas, entretanto, o poder torna-se descentrado. O poder está espalhado por toda a rede social. [...] com as teorias pós-críticas, o mapa do poder é ampliado para incluir os processos de dominação centrados na raça, na etnia, no gênero e na sexualidade (SILVA, 2011, p. 148-149).

A ampliação do mapa de poder a partir das teorias pós-críticas a qual o autor se refere, nos possibilita pensar no currículo que efetivamente reconheça a pluralidade das identidades culturais até então dominadas e silenciadas, ao tempo em que ressaltam o conhecimento como não exterior ao poder, mas como aspecto inerente ao mesmo. As teorias pós-críticas caracterizam-se por apoiarem-se numa visão pós-moderna e pós-estruturalista de análise e compreensão das relações sociais, tendo como centro os estudos culturais. E nesse sentido, possibilitam a "busca de uma articulação entre diferentes culturas no currículo escolar, de forma integrada com suas dimensões políticas, econômicas e sociais, essenciais no desvendamento de desigualdades e de hierarquias nele inscritas" (MACEDO, 2017, p. 44), o que promove uma identidade multicultural, com vistas a garantir igualdade de oportunidade para todos.

A proposta do multiculturalismo deve permear toda a reflexão do currículo no "aprofundamento de conceitos especialmente complexos e polissêmicos, tais como 'cultura, identidade cultural, diferença, diversidade cultural, identidade de fronteira, hibridização cultural' dentre outros" (CANDAU, 2012, p. 16). É nessa direção que encontra-se o desafio do currículo multiculturalista: construir uma proposta de educação que direcione 'o olhar' na contramão das marcas indeléveis imputadas aos sujeitos invisibilizados ao longo da história do sistema educacional. 
[...] todos nós precisamos passar por um processo de reeducação do olhar. O reconhecimento e a realização dessa mudança do olhar sobre o "outro" e sobre nós mesmos a partir das diferenças deve superar o apelo romântico ao diverso e ao diferente e construir políticas e práticas pedagógicas e curriculares nas quais a diversidade é uma dimensão constitutiva do currículo, do planejamento das ações, das relações estabelecidas na escola (GOMES, 2012, p. 102)

As desigualdades e preconceitos impostos às questões raciais e suas relações com o currículo, devem ser revistas e resignificadas, para além dos devaneios que imprimem uma visão romântica e utópica às práticas pedagógicas; mas que assegurem o lugar das 'minorias marginalizadas', que assegurem a sua diversidade cultural, a sua história, nos espaços educativos e consequentemente na sociedade.

Para Munanga (2012, p. 346), a discussão sobre "multiculturalismo deve levar em conta os temas da identidade racial e da diversidade cultural para a formação da cidadania como pedagogia antirracista”, o que corrobora para a construção de um currículo que considere a representação positiva do povo negro e de uma pedagogia da diversidade, calcada no respeito pela história do africano, pela compreensão e valorização de sua luta, sua resistência e seus conhecimentos.

Entretanto, cabe salientar que, embora as teorias pós críticas que ancoram o currículo numa perspectiva multiculturalista, defendam a diversidade, os mecanismos de controle e manutenção continuam atuando, por meio de práticas didático pedagógicas dessintonizadas, com "[...] adoção de programas e projetos específicos voltados para a diversidade étnico racial realizados de forma aleatória e descontínua" (GOMES, 2012, p. 117), ainda aceitas e desenvolvidas no âmbito educacional.

Em torno dessa constituição das teorias pós-críticas, a inserção da temática História e Cultura Afro-Brasileira, bem como o princípio da Afrocentricidade podem contribuir significativamente para a construção e implementação efetiva de um currículo que resgate a história e a cultura africana e afro-brasileira, seus referenciais identitários em favor de uma educação que prime pela diversidade étnica e racial.

\section{Formação docente e Currículo afrocen- trado}

As discussões apresentadas até então nos desafiam a pensar nos diversos fios que se entrelaçam nas incertezas e singularidades da educação na contemporaneidade, dentre elas a formação de professores. Isso exige repensar concepções e práticas pedagógicas simplistas e fragmentadas, tecendo relações ancoradas nas teorias do campo científico que alicerçam o processo formativo e dos saberes científicos, curriculares e da experiência de professores, que consolidem o diálogo entre teoria e prática, de forma imbricada e não dicotômica. Uma formação que potencialize a autonomia crítica e reflexiva do professor, que desencadeie sua curiosidade singular na busca da compreensão para enfrentar os limites e 
possibilidades que desafiam a prática pedagógica cotidiana.

Nesse contexto, um dos desafios atuais é o de aprofundar os saberes e conhecimentos sobre a formação inicial e continuada de professores. Isso revela uma preocupação com o itinerário formativo de profissionais de diversas áreas que atuam ou atuarão na educação básica, haja vista que ainda há muito que discutir sobre conhecer e reconhecer a importância da formação docente como pilar para o processo de ensino e aprendizagem, principalmente no que tange ao reconhecimento e valorização da diversidade. Sendo assim, urge desconstruir a ideologia da homogeneidade, rompendo com a modelagem, com padrões estereotipados, construindo práticas pedagógicas que dialoguem com a diversidade, com as culturas marginalizadas historicamente. Um exercício "abstruso, uma vez que geralmente esbarra na dificuldade do professor em atuar de maneira diferente da qual está acostumado, considerando que sua trajetória foi pautada na uniformização e na determinação" (ALMEIDA, 2014, p. 49).

A docência deve ser entendida como um trabalho intelectual realizado além do que é prescrito, como uma atividade em que o professor possa desenvolver uma visão crítica dos conhecimentos elaborados em um constante questionamento, que $o$ inquiete e o mobilize no sentido da investigação, possibilitando-lhe dar significado a suas ações, vivenciando a função como uma experiência em busca da construção de conhecimentos e de uma cultura própria da profissão (ALMEIDA, 2014, p. 48).
A análise do processo formativo do professor, desvela a importância de se pensar a formação numa abordagem que possa ir além da natureza instrumental e meramente técnica e acadêmica, mas, sobretudo, que produza um outro tipo de conhecimento, mais próximo das realidades educativas e do cotidiano. Um processo de transformação em que as relações são tecidas por uma complexidade de fios que estabelecemos com o mundo, com os nossos pares e conosco mesmo, na medida em que empreendemos uma jornada entre caminhos que se entrecruzam simultaneamente, formando uma ressonância entre as diferentes experiências vividas que nos constituem professor(a).

É fundamental ao professor, possuir um conjunto de saberes abrangentes, didáticos e transversais, provenientes da sua formação inicial e contínua que possibilite "[...] a sua capacidade de informação crítica, habilitado a ler e a interpretar a sua realidade e seu entorno; capacidade de atualização incessante, sobre o fulcro do 'aprender a aprender', num esforço sempre renovado de não ceder à instrumentalização subalterna" (DEMO, 2009, p. 30).

Os diferentes sentidos e significados, muitas vezes idênticos e às vezes excludentes, dão ao conceito de formação um sentido polifônico "[...] ora entendido como instruir, ora como treinar ou como educar, não marca, na maioria das vezes, o campo semântico desta palavra" (SOUZA, 2006, p. 37). Assim, igualar formação com educação, formação permanente, capacitação, formação profissional, conduz, muitas vezes, a um reducionismo no pensar a formação como experiência da própria existência hu- 
mana, “[...] projeto de produção da vida mediada pelos sentidos estabelecidos pelos sujeitos no processo de formação" (p. 37). A dimensão profissional é tecida durante o processo de escolarização/formação e aprendizagem dos sujeitos, o que demanda estudo e persistência na busca de conhecimento, favorece um espaço de interação entre as dimensões pessoais e profissionais, ao tempo em que promove saberes e possibilita mudanças.

O modelo de racionalidade técnica implantado no currículo profissional de formação de professores baseia-se em teorias e técnicas da ciência básica e aplicada, em uma perspectiva dicotômica de formação, revelando uma postura de domínio dos que detém o poder das ideias, alicerçadas em "ideologias instrumentais" que reduzem o professor a técnico, que aplica as regras do conhecimento científico com práticas descontextualizadas ao "administrar e implementar programas curriculares, mais do que desenvolver ou apropriar-se criticamente de currículos que satisfaçam objetivos pedagógicos" (GIROUX,1997, p. 158). Neste sentido, deve-se considerar as condições históricas, culturais e sociais nas quais se exerce a profissão; condições que servem de base para a prática docente.

Ao contrapor com a racionalidade técnica, o modelo de racionalidade prática, considera a teoria e a prática como norteadores da formação docente, posto que devem estabelecer uma relação simultânea recíproca de autonomia e de dependência entre elas. A formação é repensada e o professor passa a refletir, criar e decidir sobre a sua prática pedagógica, desde os primeiros momentos da formação. Desse envolvimento com a realidade prática originam-se problemas e questões que devem ser levados para discussão nas disciplinas teóricas, de forma concomitante e articulada" (PEREIRA, 1999, p. 113), possibilitando a reflexão, embasada na conscientização, na crítica, na problematização.

O caráter dialético, a reflexão e a criticidade são basilares no modelo de racionalidade crítica, onde teoria e prática se complementam como partes de um mesmo processo. O que possibilita uma formação para que o professor desenvolva o "conhecimento sobre o ensino que reconheça e questione sua natureza socialmente construída e o modo pelo qual se relaciona com a ordem social; analisar as possibilidades transformadoras implícitas no contexto social" (CONTRERAS, 2002, p.157-158). Centrado na reflexão, na crítica e na investigação sobre a prática, o professor, enfrenta desafios e limites, mobiliza saberes e competências para além da construção de habilidades, na busca de mudanças e transformações em si e nas estruturas sociais que condicionam a educação.

No âmbito formativo, os saberes construídos a partir dos conhecimentos otimizados, deverão articular-se com o exercício profissional, alicerçado na formação, participação e experiência, atento às exigências da educação advindas das demandas sociais próprias de uma sociedade em constante processo de mudança. Entretanto, na contemporaneidade, ainda é notória a fragilidade tanto na estruturação dos cursos de formação inicial como na forma- 
ção continuada de professores, no que se refere à composição curricular das Instituições de Ensino Superior - IES quanto à obediência às Diretrizes Curriculares Nacionais - DCN para os Cursos de Formação de professores-licenciatura (Brasil, 2011)

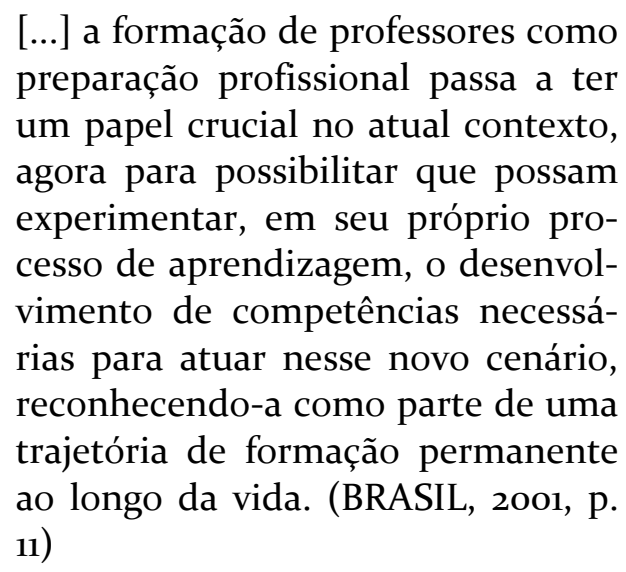

Cabe ressaltar que mesmo diante das fragilidades, a Lei 10.639/03 trouxe a necessidade de "mudanças na política de formação inicial e continuada para profissionais de educação que deverá, de acordo com as prescrições e orientações normativas, contemplar o estudo da diversidade étnicoracial" (BRASIL, 2004, p. 29), fomentando pesquisas, desenvolvimento e inovações na temática das relações étnicoraciais, nos cursos de formação docente, o que dialoga diretamente com o ideal afrocêntrico como "possibilidade de maturidade intelectual e uma forma de ver a realidade como algo que abre novas caminhos para a compreensão humana (ASANTE, 2009, p. 5). Um currículo que atenda a diversidade e as diferentes culturas, sobretudo que visibilize e aprofunde reflexões concernentes as matrizes africanas em suas diferentes vertentes, possibilitando uma prática docente atual/futura que evidencie a ressignificação de metodologias e de conteúdos necessários a formação afro-brasileira.

Muito já denunciamos sobre a rigidez das grades curriculares, o empobrecimento do caráter conteudista dos currículos, a necessidade de diálogo entre escola, currículo e realidade social, a necessidade de formar professores e professoras reflexivos e sobre as culturas negadas e silenciadas nos currículos. (GOMES, 2012, p. 102)

A ruptura paradigmática enseja uma perspectiva de conhecimento e valorização da cultura africana, em especial o entendimento de que os africanos foram e são produtores de conhecimento, sem a hierarquização dos saberes, mas sobretudo considerando "as concepções, representações e estereótipos sobre a África, os africanos, os negros brasileiros, e sua cultura" (GOMES, 2012, p. 106). O que pode ser evidenciado em um currículo afrocentrado para os cursos de formação docente que contemplem "fundamentos apoiados na história dos povos africanos, numa linha filosófica africana, em investigações sociológicas que analise-as em sociedades africanas e afrodiaspóricas, e, numa psicologia afrocentrada" (NOGUERA, 2010, p. 6), que subsidiem não apenas a formação acadêmica mas, a prática pedagógica docente atual/futura destes profissionais em formação, que considere e valorize uma proposta curricular teóricametodológica, centrada na afrocentricidade

Nesta esteira, ao adotarem a perspectiva transversal afrocêntrica, torna-se fundante que os currículos para a formação de professores, nas IES, considerem 
[...] dois fundamentos epistemológicos: um cognoscivo, em que o conhecimento teórico da cultura africana é valorizado como instrumento direcionado à assunção de uma identidade anti-hegemônica, e um fundamento praxiológico, onde, como consequência da assunção identitária, se alcança uma intervenção na prática educacional e na atuação pedagógica (SILVA, 2016, p. 260).

Ao corroborar com os referidos fundamentos epistemológicos, Asante (2009), assevera que cabe ao professor observar e trabalhar a história da África considerando a cultura própria dos africanos, suas histórias, seus contextos e singularidades, demarcando suas significativas contribuições a formação do povo afro-brasileiro.

[...] vendo-se como sujeitos, em vez de objetos da educação - seja na biologia, na medicina, na literatura ou nos estudos sociais - os estudantes afro-americanos passam a ver-se não apenas como quem busca o conhecimento, mas participantes desse processo. Na medida em que todas as áreas são adaptáveis a uma abordagem afrocêntrica, os estudantes afro-americanos podem se ver como sujeitos centrados em relação à realidade de qualquer disciplina (SILVA, 2016, apud ASANTE, 1991, p.171).

Isto implica não apenas ressignificar modelos de formação pautados em parâmetros fixos e predeterminados, em que a teoria se distancia da prática, rompendo paradigmas em que o discurso hegemônico eurocêntrico mas, uma mudança de atitudes de questionamento, reflexão e experimentação por parte do professor. Um compromisso com a descentralização dos currículos acadêmicos/escolares no sentido de tornálos, a um só tempo, menos etnocêntricos e, consequentemente, mais críticos e afrocêntricos, rompendo com o silenciamento em torno do continente africano.

\section{Nas considerações finais, o olhar emer- ge para mudanças...}

O currículo para ser transformado, requer um olhar atento e desprovido de estereótipos para ser compreendido em sua complexa relação de construção, considerando as transformações sofridas por este através dos tempos, suas idiossincrasias, assim como a mudança de paradigmas. Nesta perspectiva, torna-se fundante, pensar o currículo que transponha o formal e o tradicional, que proponha conteúdos que derivam de outros referenciais, considerando toda uma dinâmica das relações estabelecidas, voltando o olhar para o hibridismo sociocultural vivenciado pelos sujeitos no cotidiano. O que implica no repensar a formação de professores rompendo com velhas concepções e práticas pedagógicas que caminham na linearidade e na normatividade.

É nesse sentido que o papel a ser assumido pelo docente na contemporaneidade requer dele uma formação que possibilite questionar e ressignificar suas representações, refletir a partir de vivências, sobre a complexidade da tarefa de educar, interferindo assim nas atitudes, concepções e procedimentos do exercício profissional. 
Podemos apreender que a formação de professores, alicerçada em um currículo afrocentrado constitui-se como um terreno fértil para uma educação crítica voltada a conceitos e preconceitos produzidos e reproduzidos socialmente pela cultura eurocêntrica. Um currículo voltado a "deszoomorfização de africanas(os) e afrodescendentes, fomentando a esperança” (NOGUERA, 2010, p. 14) de uma prática pedagógica em que a espe- rança dê lugar a concretização, não de um sonho distante mas, de uma efetiva realidade que se apresenta aos 'nossos olhos', que toma como perspectiva a cultura e a história dos povos africanos e afro-brasileiros de maneira positiva, superando as superficialidades e distorções ainda presentificadas no currículo.

\section{Referências}

ALMEIDA, Carla Verônica Albuquerque. A professora nos entremuros do Cárcere. Tese (Doutorado em Educação) - Programa de Pós-Graduação em Educação e Contemporaneidade - PPGEDUC - Departamento de Educação - DEDC/CAMPUS I, Universidade do Estado da Bahia - UNEB, Salvador, 2014, $246 f$.

ASANTE, Molefi Kete. Afrocentricidade: notas sobre uma posição disciplinar. In: NASCIMENTO, Elisa Larkin. Afrocentricidade: uma abordagem epistemológica inovadora. São Paulo: Selo Negro, 2009. (Sanfoka: matrizes africanas da cultura brasileira).

AZEVEDO, Amailton Magno. Qual África ensinar no Brasil? Tendências e perspectivas. Projeto História, São Paulo, n. 56, pp. 233-255, mai.-ago. 2016.

BENEDICTO, Ricardo Matheus. Afrocentricidade, educação e poder: uma crítica afrocêntrica ao eurocentrismo no pensamento educacional brasileiro. Tese (Doutorado em Educação) - Programa de Pós-Graduação em Educação - Faculdade de Educação - Universidade do São Paulo - USP, Salvador, 2016, 298f.

BERTICELLI, Ireno Antonio. Currículo: tendências e filosofia. In: COSTA, Marisa Vorraber. (Org.). O currículo nos limiares do contemporâneo. 3 Ed. Rio de Janeiro: DP\&A, 2001. p.159-176.

BRASIL. Ministério da Educação. Conselho Nacional de Educação. Conselho Pleno. Parecer no CNE/CP o09/2001. Diretrizes Curriculares Nacionais para a formação de professores da Educação Básica, em nível superior, curso de licenciatura, de graduação plena. 2001.

BRASIL. Diretrizes Curriculares Nacionais para a Educação das Relações Étnicoraciais e para o Ensino de História e Cultura Afro-Brasileira e Africana. Brasília, SECAD, 2004. 
BRASIL. Lei n. 10.639 de o9 de janeiro de 2003. Inclui a obrigatoriedade da temática "História e Cultura Afro-Brasileira” no currículo oficial da rede de ensino. Diário Oficial da União, Brasília, 2003.

CANDAU. Vera Maria. Didática crítica intercultural: aproximações. Petrópolis, RJ: Vozes, 2012.

CONTRERAS, José. A autonomia dos professores. São Paulo: Cortez, 2002.

DEMO, Pedro. Desafios Modernos da Educação. 26. ed. São Paulo: Vozes, 2009.

EYNG, Ana Maria. Currículo e avaliação: duas faces da mesma moeda na garantia do direito à educação de qualidade social. Revista Diálogo Educacional, V. 15, n. 44, Champagnat, Curitiba, 2015.

FREIRE, Paulo. Pedagogia do oprimido. 35. ed. Rio de Janeiro: Paz e Terra, 2003.

GENTILLI, Pablo. O direito à educação e as dinâmicas de exclusão na América Latina Educação e Sociedade. Educação e Sociedade. Campinas, Vol. 30, núm. 109, p. 1059-1079, set./dez. 2009. Disponível em <http: www.cedes.unicamp.br>. Acesso em 28 de abr. 2019.

GIROUX, Henry A. Os Professores como intelectuais transformadores: rumo a uma nova pedagogia crítica da aprendizagem. Porto Alegre: Artes Médicas, 1997.

GOMES, Nilma Lino. Relações étnico-raciais, educação e descolonização dos currículos. Currículo Sem Fronteira, v. 12, n. 1, p. 98-109, jan./abr. 2012.

MACEDO, A. Negar, silenciar, apagar: a gestão escolar frente à educação antirracista. Revista da ABPN, Goiânia, v. 9, n. 22, p. 385-408, 2017.

MAZAMA, Ama. A Afrocentricidade como um novo paradigma. In: Elisa Larkin. Nascimento (Org.). Afrocentricidade: uma abordagem epistemológica inovadora. São Paulo: Selo Negro, 2009. p.111-127.

MUNANGA, Kabengele. Diversidade, identidade, etnicidade e cidadania. 2012, p. 01-13. Disponível em: <http://www.acaoeducativa.org.br/fdh/wp-content/uploads/2012/og>. Acesso em 03 mai. 2019.

NOGUEIRA, Renato. Afrocentricidade e educação: os princípios gerais para um currículo afrocentrado. Revista África e Africanidades. Ano 3. n.11, novembro, 2010. Disponível em: http://www.africaeafricanidades.com.br/documentos/pdf. Acesso em 22 abr. 2019.

PEREIRA, J. Formação de profissionais da educação. Revista Educação e Sociedade. Campinas, n 68, 2ª edição, 1999.

SACRISTÁN, J. Gimeno. Currículo, uma reflexão sobre a prática. 3. ed. Porto Alegre: Artmed, 2000. 
SANTOMÉ, Jurjo Torres. As culturas negadas e silenciadas no currículo. In. SILVA, Tomaz Tadeu. (Org.). Alienígenas na sala de aula: uma introdução aos estudos culturais em educação. Petrópolis: Vozes, 1995. p. 159-189.

SILVA, Tomaz Tadeu da. Documentos de Identidade: Uma Introdução às Teorias de Currículo. 3 ed. Autêntica. 2011.

SILVA, Maurício. Afrocentricidade: um conceito para a discussão do currículo escolar e a questão étnico-racial na escola. Revista Educacional, Campinas, 21, mai/ago, 2016, p. 255261.

SOUZA, Elizeu Clementino de. O conhecimento de si: estágio e narrativas de formação de professores. D\&A/Uneb, 2006.

TYLER, Ralph. Princípios básicos de currículo e ensino. Porto Alegre: Globo, 1999.

Recebido em: 05/06/2019

Aprovado em: 31/10/2019 